\title{
Do we need gene therapy?
}

SIR - A serious imbalance is creeping into discussions on human embryo research and the direction of clinical genetics.

The first paragraph of the Warnock report on human fertilization and embryology (para 1.1) says "It is now possible to observe the very earliest stages of human development, and with these discoveries came the hope of remedying defects at this very early stage"; a theme developed in paragraph 12.15. Edwards and Puxon (Nature 310, 179; 1984) suggest that "such research could open undreamtof-vistas of improvement and amelioration for mankind"; and Weatherall concludes his comment on gene transfection (Nature 310,451 ; 1984) with the statement "offers major encouragement to those who believe that the ultimate goal of clinical genetics is gene replacement therapy, rather than termination of pregnancy".

The belief that the ultimate goal of all clinical practice is to remedy the defect seems to be common among molecular geneticists as well as physicians involved in the treatment of genetic and partly genetic disorders. Patients and parents usually go along with this philosophy when the diagnosis is made after birth, or late in pregnancy, but it would be wrong to assume that this traditional goal of clinicians is necessarily appropriate for embryos with genetic defects.

Physicians and surgeons tend to forget that no matter how grateful patients or parents are for the effort and skill put into treatment, or how desperately they long for the research "breakthrough" that will allow improved treatment, they would much prefer to have no need of doctors at all. People do not want their babies to be medical successes, they want them to be normal. It will be argued that treatment will make them normal. But complete success can rarely be guaranteed in advance, and there is usually a considerable gap between what doctors and what patients regard as a success (although the latter may be too polite to say so).

The goal of correction of genetic defects rather than termination of pregnancy implies detection of the affected embryo in the first trimester of pregnancy even if therapy is carried out later. However, as someone who has close contact with couples making decisions about prenatal diagnosis and selective abortion, I believe that once the abnormality has been detected, most couples will opt for termination of pregnancy and "trying again", rather than chance treatment of the embryo or fetus. There is already widespread acceptance of selective abortion in early pregnancy, which can only be enhanced with the general realization that about $\mathbf{4 0}$ per cent of conceptions are lost as natural miscarriages (D.K. Edmunds et al. Fertil. Steril. 38, 447; 1982), and close on half of early miscarriages are chromosomally abnormal
(E.D. Alberman and M.R. Creasy J. med. Genet. 14, 313; 1977). The advent of home pregnancy testing kits that confirm a pregnancy within two weeks of conception can only encourage the view that selective abortion is Nature's way.

It seems quite wrong for clinicians and scientists to assert that the goal for clinical genetics is gene replacement, when many, probably the majority of couples would not choose this option. It can only be one of several aims of clinical genetics. Certainly "the need to develop methods of gene replacement in embryos" cannot be regarded as a reason for allowing the creation of human embryos specifically for research purposes, until such a need has been demonstrated. It should also be remembered that 7 out of 16 members of the Warnock committee were against the creation of human embryos specifically for research purposes.

Mothercare Unit of Paediatric Genetics, Institute of Child Health,

University of London,

30 Guilford Street,

London WCIN IEH, UK

\section{Science journalism}

SIR - The editorial policy of Nature in declining for publication material that has already been communicated to lay or popular news media has provoked hostile reaction from those media, as exemplified by Mr Leif Robinson's letter (Nature 16 August, p. 536).

When I was first engaged in scientific research, it was accepted without question that one did nothing to invite publication of one's work outside the scientific literature-of-record, not only for fear of misrepresentation but also because it was regarded as unprofessional self-advertisement. Mr Robinson claims that by adhering to this ethic Nature is guilty of restricting the public's right to know the results of research.

$\mathrm{He}$ attempts to justify this assertion by arguing first that misrepresentation has become less of a danger with the recruitment of better qualified scientific journalists, and then that they can misrepresent research results just as easily after proper scientific publication as before. Clearly the two arguments largely nullify each other. The fact is that misrepresentation is less harmful if the true record has been published so that anyone who really cares about the truth can refer to it. As an aside, I do agree that there are now some excellent and professional scientific journalists, but the fact that coverage of science by the lay media in general stil leaves much to be desired is illustrated by the example of the ludicrous reports of Soviet science which sometimes appear in otherwise respected newspapers "from our Moscow Correspondent"

Mr Robinson then destroys his own case by stating that science journalists will "ferret out stories", since to make a scientific result into a journalist's story is in itself distortion of a fundamental kind; there can of course be legitimate stories about science but that is different. Denial of the public right to information lies in giving the public a substitute account, not in insistence that what is published is a true professional and authentic record.

I conclude that Nature's policy is correct even in relation to the considerations raised by $\mathrm{Mr}$ Robinson. In addition, and despite scientists who have attracted repeated press notice having behaved with integrity in not exploiting this attention unfairly, the climate for scientific research will remain healthier to the extent that young scientists are encouraged to publish for peerjudgement not public acclaim.

\section{Department of Cybernetics,}

PETER FELlgetT

\section{University of Reading, Reading RG6 $2 A L$, UK}

SIR - It ill becomes Leif Robinson (Nature 16 August, p.536) to upbraid John Maddox for reminding scientists and others of the fundamental importance of their voluntary code of practice regarding the announcement and publication of new results. It is natural of course that Robinson should do so, given that he evidently regards peer review as a potentially restrictive practice obstructing the free flow of information between scientists, the public and the press. The fact that scientific peers today often do look upon themselves as a kind of thought police, imperially appointed to defend some imagined consensus view rather than subjecting arguments to independent rational review, may partially condone the error. Nevertheless, it is sad that Leif Robinson, editor of a widely read popular journal of science, so fails to appreciate the true role of peer review in the scientific process that he appears to advocate its omission.

At the same time, another problem exists which Robinson's complaint does perhaps more directly address, namely the ethical dilemma that sometimes confronts scientists concerning publicity between the instant of acceptance and the instant of actual publication. In this age, there are scientists and institutions who no longer feel restrained by traditional practices and who seek increasingly to pre-empt such kudos as might otherwise accrue to the publishing journal by organizing their own publicity. If the editors of Nature wish to maintain their reputation as publishers of original new scientific results, it seems that they can succeed in this aim only by so marshalling modern technology as to reduce the interval between acceptance and publication to the absolute minimum.

\section{S.V.M. Clube}

Royal Observatory,

Blackford Hill,

Edinburgh EH9 $3 H J$, UK 